\title{
THE DEVELOPMENT OF THE ACCESSORY SINUSES OF THE NOSE..$^{1}$
}

\author{
By Lewis A. Cofrin, M.D., \\ SURGEON TO THE MANHATTAN EYE, EAR, AND THROAT HOSPITAL, NEW YORK.
}

I SHALL present a series of pictures illustrating the stages of development of the various sinuses, but before so doing I wish briefly to refer to the literature on the subject, quoting only such parts as apply to the time of the appearance of the various sinuses.

\section{THE FRONTAL SINUS.}

Quain says: “The frontal sinuses appear about the seventh year and continue to increase in size up to old age."

Lothrop: "At birth the frontal bone is in two portions; the sinus has not yet appeared; the frontal eminences are prominent. As the child grows, the sinuses develop slowly and the general shape of the head and frontal region changes; at puberty the sinuses are practically developed and the frontal area has assumed its adult form." From a study of 125 skulls (250 sinuses) he found a frontal sinus always present, being confined to the orbital portion of the bone in cases in which by others it is said to be absent, this cell opening into the nose in conformity with one of the three modes of communication between the frontal sinus and the nose. This condition he found in about 3 per cent. of his examinations, at least on one side. I have in my possession a skull in which there is no cavity either in the vertical or orbital portion of the bone.

Turner says: "The sinuses (frontal) are not present at birth. Some difference of opinion has been expressed with regard. to their first appearance. This is probably due to the fact that some observers recorl the period at which the sinus begins to develop, while others note the age at which the sinus is first recognized as a distinct cavity in the vertical portion of the frontal bone. It is generally held that the frontal sinus commences to develop at the end of the first year or at the beginning of the second year of life. As it extends upward and outward, expanding the frontal tables in its growth, it reaches in the sixth or seventh year above the frontonasal suture, and can be recognized at that age as a distinct cavity above the root of the nose."

The above, he states, are the observations of Steiner. He quotes Symington as reporting two cases in which fairly well developed sinuses were found at the age of nine and thirteen years. Symington did not find a frontal sinus in the vertical portion of the bone in

\footnotetext{
1 Read before the Tenth Annual Meeting of the American Association of Laryngology, Rhinology, and Otology, at Chicago, May 30, 81, and June 1, 1904.
} 
children under six years. Turner failed to find evidence of the sinus above the frontonasal and maxillary sutures in two cases, aged six and seven years. He warns against making deductions from a few observations, as sinuses are occasionally absent in adult life.

St. Clair Thompson (Posey and Wright) says: "The frontal sinus is absent at birth and during infancy; it is seldom evident before the seventh or eighth year." Dr. Thompson refers evidently to a distinct cavity in the vertical portion of the bone.

Kölliker says: "The frontal sinuses do not develop until after birth, and not fully until puberty. They continue to grow for a long time after."

Mouret says: "An absorption of the frontal diploë is produced at the same time the mucosa of the ethmoid diverticulum prolongs itself into the cavity for the purpose of lining it, prolonging the nasal cavity beyond the ethmoid."

It will be seen by the quotations given that there is some difference of opinion. Turner, Mouret, and others hold that the frontal sinus results from the upward expansion of the etbmoid labyrinth, while Lothrop, who has done an immense amount of work on the anterior ethmoid cells and the frontal sinus, sees, as I understand him, in the frontal sinus an independent cavity, always present and always opening independently into the nose.

In 1872 Steiner, with a considerable original work as a basis, contributed a valuable article on the development and anatomy of the frontal sinus. On its development he sums up thus: "The development of the ethmoid labyrinth at the end of the first year and beginning of the second year into gradually increasing spaces in the diploe of the nasal portion of the frontal bone is simultaneous with the growth of the frontal bone downward, so that at the sixth or seventh year we can find a frontal sinus about the size of a pea between the two layers of the frontal bone, as a result of the combined growth and out of which the diploë of the frontal bone fades away to be replaced by the cavities from the ethmoid labyrinth."

Dr. Steiner speaks of this resorption of the frontal diploë as due to pressure, but does not say from what source the pressure comes, whether it be the force of expansion from the natural development of the ethmoid labyrinth or whether it be a pneumatic pressure.

Tillaux is quoted by Steiner as stating that the frontal sinus develops from the eleventh to the thirteenth year. This Steiner has shown to be wrong.

It has seemed to me in my work that I have noticed that where there is obstructed breathing, especially from adenoid growths, there is a poor development of all the pneumatic sinuses, and I have wondered if in this we could not find the cause of the extension of the ethmoidal cells into the diploe of the frontal bone. We may have no frontal sinus, or one frontal sinus in any case, and it may 
be developed as the result of the extension of the infundibulum or any other of the anterior ethmoidal cells (Mouret).

The diploë of the frontal bone manifestly is possessed of no inherent principle which causes its resorption. Neither does the capacity to expand into it seem to belong to any particular ethmoidal cell. It seems rather an accident. May it not be the weight or contiguity of the bone covering the various ethmoidal cells that determines which one is to prolong itself into the frontal bone? That is, given a cell with an incomplete or weak bony covering of its mucous lining, will it not expand under pnemmatic pressure and, impinging on the diploë of the frontal bone, cause resorption of the cancellous tissue and the consequent cavity?

This peculiar development and expansion does not manifest itself either until just at that age at which children begin blowing the nose, etc., thereby causing increase of the intranasal pressure. The infundibulum is, I believe, usually a blind duct, limited at its upper extremity by mucous membrane only; hence it more frequently than any other cell pushes its way into and forms the cavity of the frontal bone.

\section{THE SPHENOIDAL SINUS}

Quain says: "The spongy bone begins to ossify in the fiftl month. At birth each consists of the small sagittal lamina resting against the presphenoidal, continuing posteriorly into the lateral projection which is hollowed in front for the sphenoidal sinus, the latter having been formed as the recess of the mucous membrane of the nose at the end of the third month. By the third year the bone has entirely surrounded the sinus, forming all osseous capsule with an anterior opening-the sphenoidal foramen."

Turner simply states that the sinuses are not present at birth.

Symington says: "They begin to be formed as the spongy tissue of the bone about the third year. In a child of six he found them quite well developed."

St. Clair Thompson (Posey and Wrigbt), speaking of their development, states that they are not present at birth. Their appearance is given by different authors as at the third year (Steiner), the seventh (Laurent), and the twentieth (Tillaux).

Sieur et Jacob (p. 379) say: "There are many opinions by different writers."

\section{THE ETHMOIDAL LABYRINTH.}

Turner, in his work on the frontal sinuses and ethmoidal cells, does not mention the development of the latter.

What Lothrop says of the embryology of the ethmoid bone would suggest that the cells first appear and grow by the development of pockets or diverticula from the cartilaginous nasal wall during the early years of infancy. 
Quain says that the ethmoidal cells appear in the sixth month as depressions of the mucous membrane, but bony walls are not developed until after birth.

Kölliker says that the ethmoid cells are already hollowed out in the foetus as early as the sixth month; at birth they are well marked.

\section{MAXILLARY SINUS. -}

The maxillary sinus exists at birth, having at that time, according to Turner, the following measurements: "Vertical diameter, $3 \mathrm{~mm}$.; transverse diameter, $7 \mathrm{~mm}$. In infancy and early childhood this small sinus occupies a position relative to the orbit entirely different

Fia. 1.

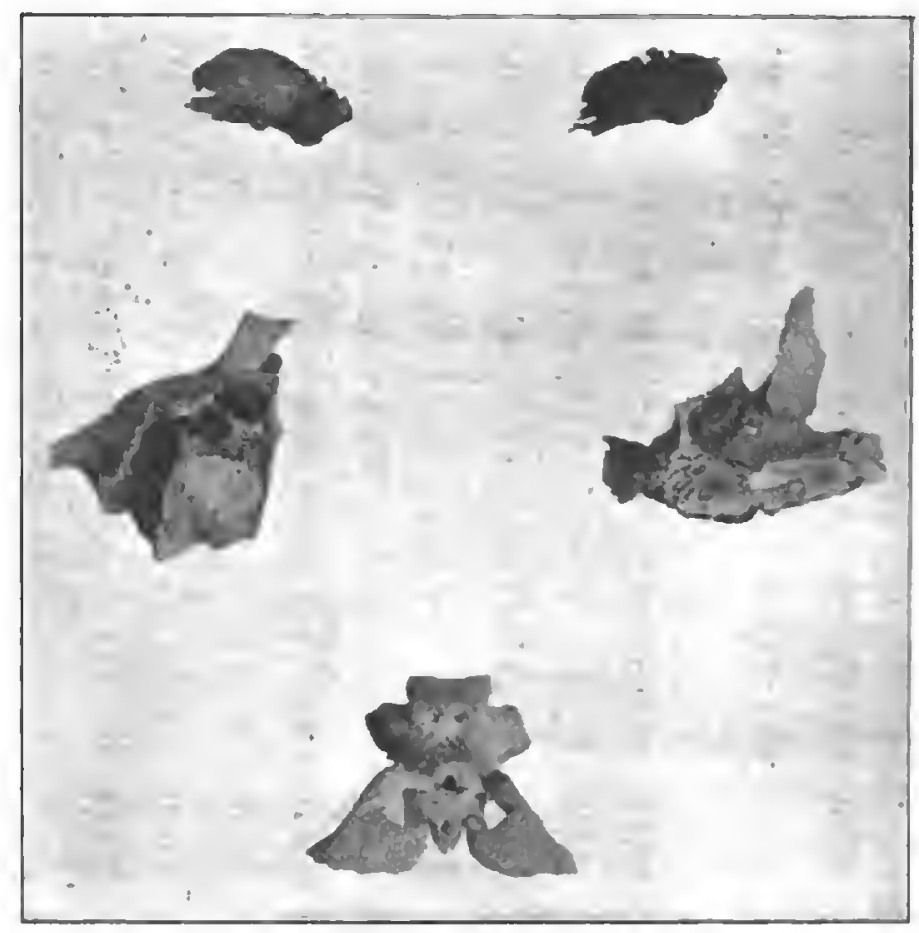

from that occupied when fully developed. At this period the body of the superior maxilla is made up almost entirely of the articular bones of the jaw, the sockets of the teeth being almost in contact with the orbital plate of the maxilla forming the floor of the orbital cavity. There is, therefore, at birth no maxillary sinus beneath the orbit." 
Knowledge of this fact is of the utmost importance in diagnosing and treating infraorbital empyema in the infant.

The discrepancies of different writers and the expression by them of the uncertainty of the time of appearance of the various sinuses,

Fiv. 2.

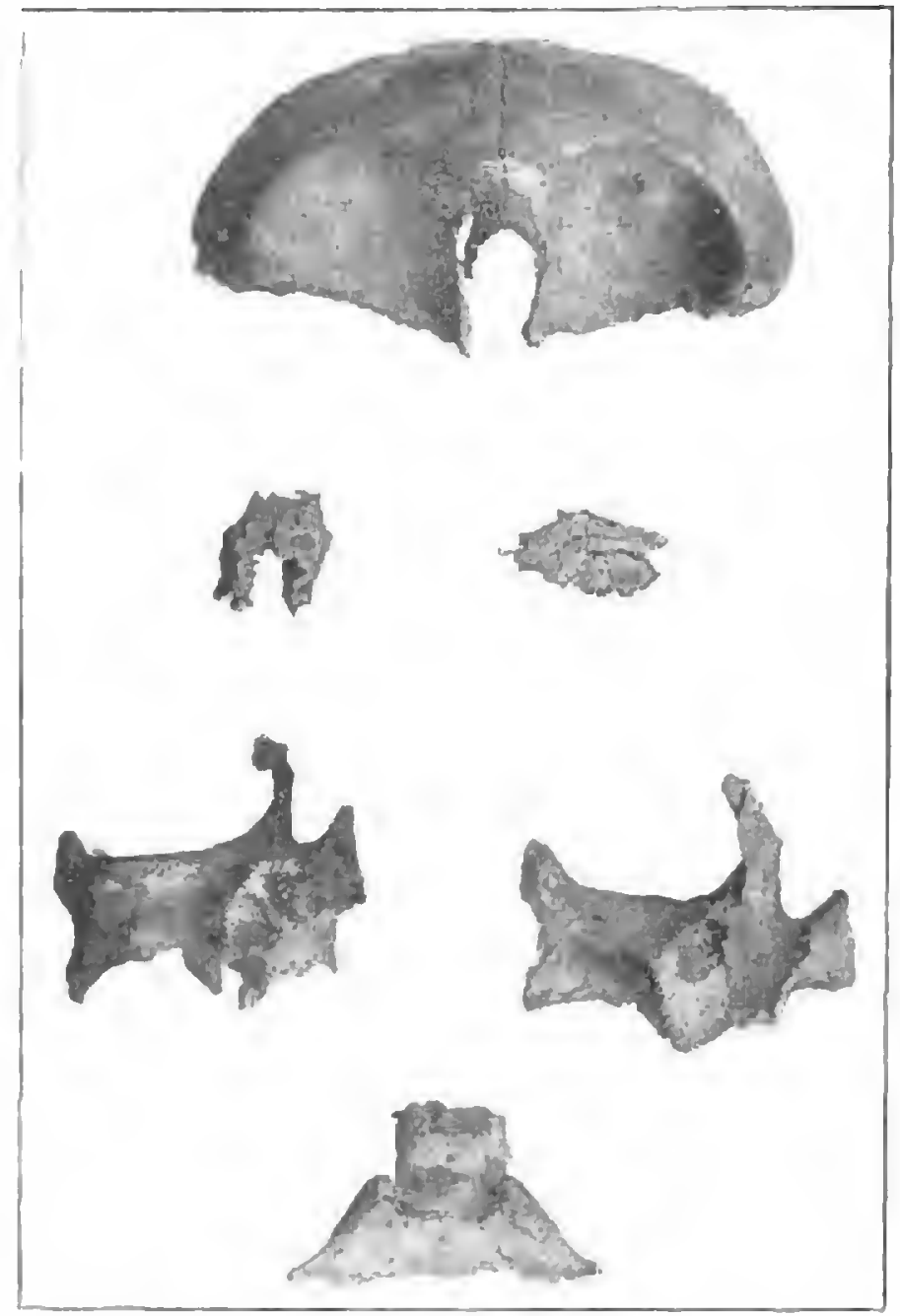

together with the confusing of the time of appearance of a sinus with the time of its full development, by students and workers in rhinology, I take it, is largely responsible for the fact that little attention has been paid to sinusitis in children. 
For practical purposes from my own experience in the examination of from twelve to fifteen skulls of infants and stillborn, from the sixth month on, and from a review of the literature on the subject, the following deductions may be made:

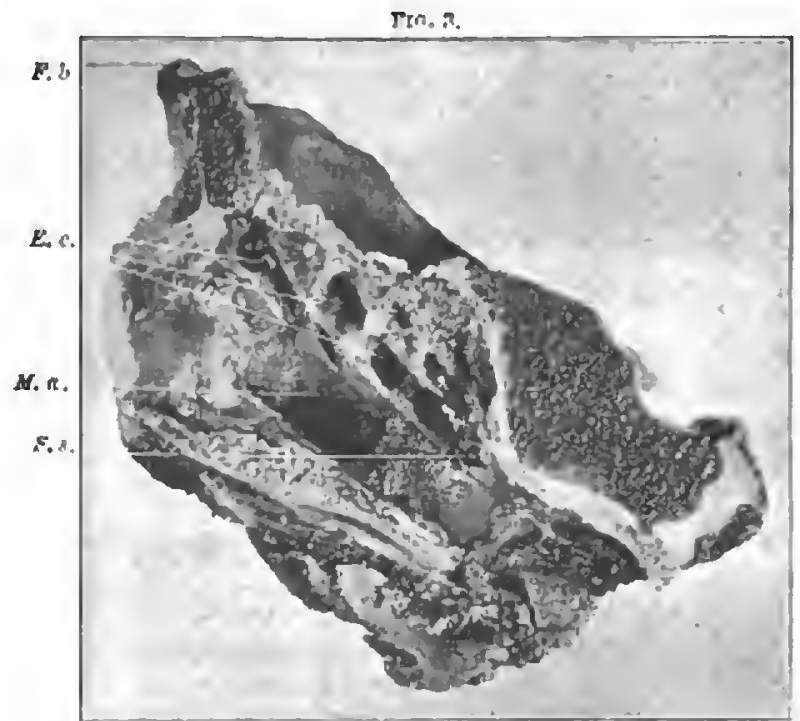

F. b., frontal bone, E. c., etbmolu cells. $\quad$. $a .$, maxillary antrum. S. 8., sphenoldal sinus.

1. But two of the accessory sinuses are present at birth-viz., the ethmoidal cells and the maxillary antrum.

2. The ethmoids and the antrum are constant sinuses.

3. The antrum does not in infancy occupy the same relative position in regard to the orbit as in later life, and cannot be reached or entered by the usual methods; neither can this be done nor

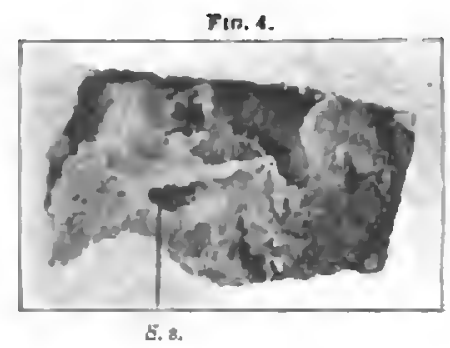

satisfactory drainage effected until after the descent of the second or permanent teeth without the destruction of a tooth socket. It makes impossible also the antral route to the ethmoid and sphenoidal sinus during this period of life. 
4. The sphenoidal sinus niakes its appearance shortly after birth, and may be found as a distinct cavity as early as the end of the first year. Practically, however, it may be considered as the most posterior of the posterior ethmoid cells.

5. The frontal sinus is not present at birth. It appears first in the orbital plate of the frontal bone between the end of the first and the beginning of the third year. Practically at this time it is the most anterior of the anterior ethmoidal cells. As I shall illustrate, it may be seen in the vertical portion as early as the end of the third year. This is early, however, and its appearance in the vertical portion should be put down from the third to the sixth or seventh year. I have openerl and operated upon the frontal sinus

FIG, 5.

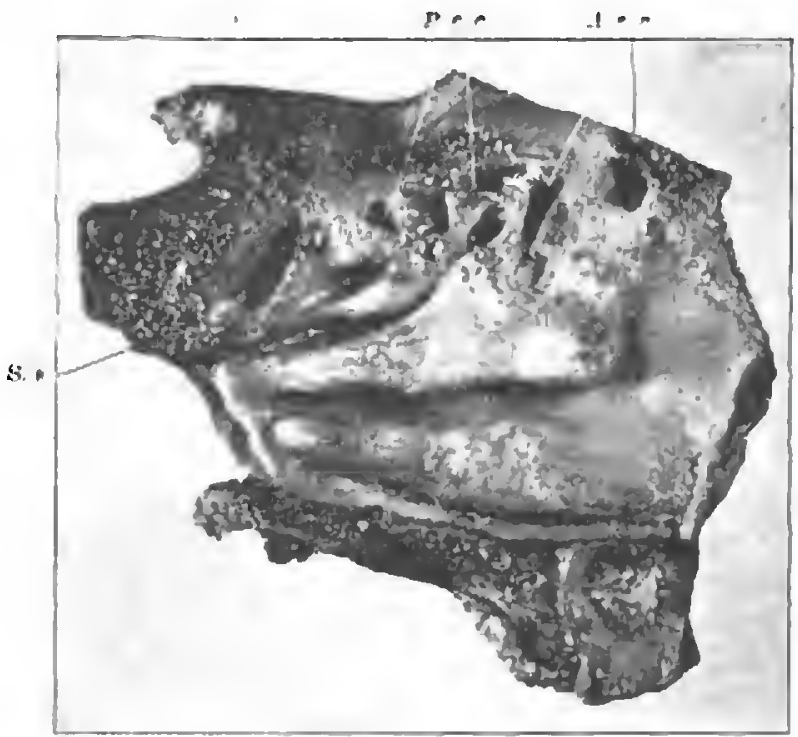

A. e. c., anterior elnmoldal ceils. P. e. c., posterior ethmoidal cells.

of a boy nine years of age which was considerably larger than the cavity of a large almond.

The accompanying figures illustrate the stage of developinent of the various sinuses at different ages from the six months' fotus to the adult.

Fig. 1 represents the sinus-containing bones of a seven months' fœtus. At the top are the two lateral masses of the ethmoid. On the next line are shown the two superior maxillary bones, the one on the right showing the nasal aspect with the antrum just posterior to the nasal process on the inner side of the orbit. On the left the bone is so posed as to show the comparatively enormous size of the tooth sockets. Below is the sphenoid bone minus the greater wings. 
Fig. 2 shows the sinus-containing bones of a seven months' child. At the top is the frontal bone with nasal bones in articulation. Below and to the left is the ethmoid bone. To its right is seen, wrong side up, the nasal aspect of the lateral mass of another child of the same age. On the third line are posed the two superior maxillary bones in the same position as in Fig. 1. At the bottom is the sphenoid bone.

Fig. 6.

F. 8.

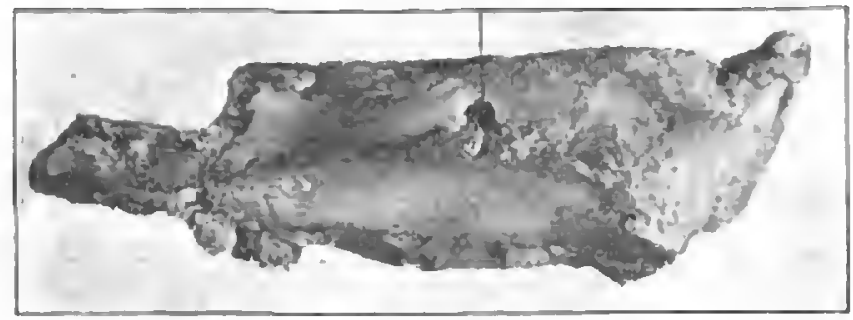

r. 8 , frontal sinus.

Fig. 3 shows the external wall of the right nasal fossa of a child one year old, the middle and superior turbinates having been removed.

Fig. 4 shows the section through the sphenoid bone, showing the sphenoidal sinus in a child one year of age.

Fig. 5 shows the external wall of the left nasal fossa of a child three years of age, the superior turbinated having been removed to show the size of the ethmoidal cells. In the back can be seen

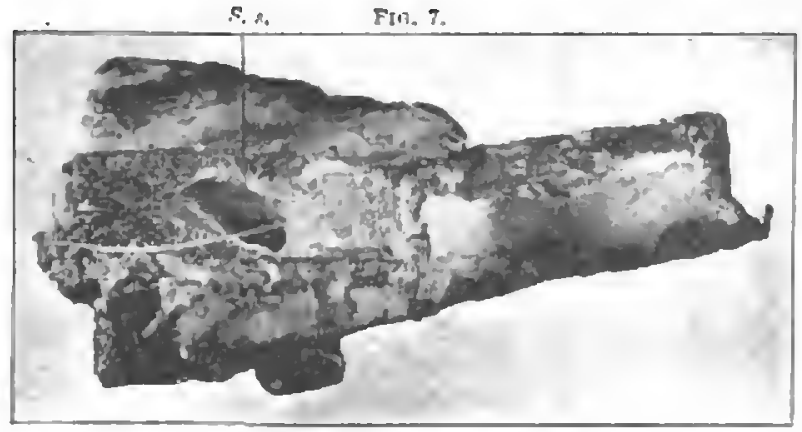

the sphenoidal sinus. The sinuses of this child seem to be well developed, and in passing I wish to call your attention to the unobstructed nasal pharynx.

Fig. 6 shows the horizontal section through the frontal bone of a child three years old, showing a cavity well within the cancellous tissue of the bone, above the frontonasal suture. ${ }^{1}$

\footnotetext{
- Since this paper was written Lothrop has reported having found a well-developed frontal sinus in the skull of a four-year-old child.
} 
Fig. 7 shows the sphenoidal sinus in same specimen as Figs. 5 and 6.

Fig. 8 shows the external wall of the right nasal fossa of a child three years old, having middle and superior turbinateds removed.

FIO. 8.

$\pi 3$,
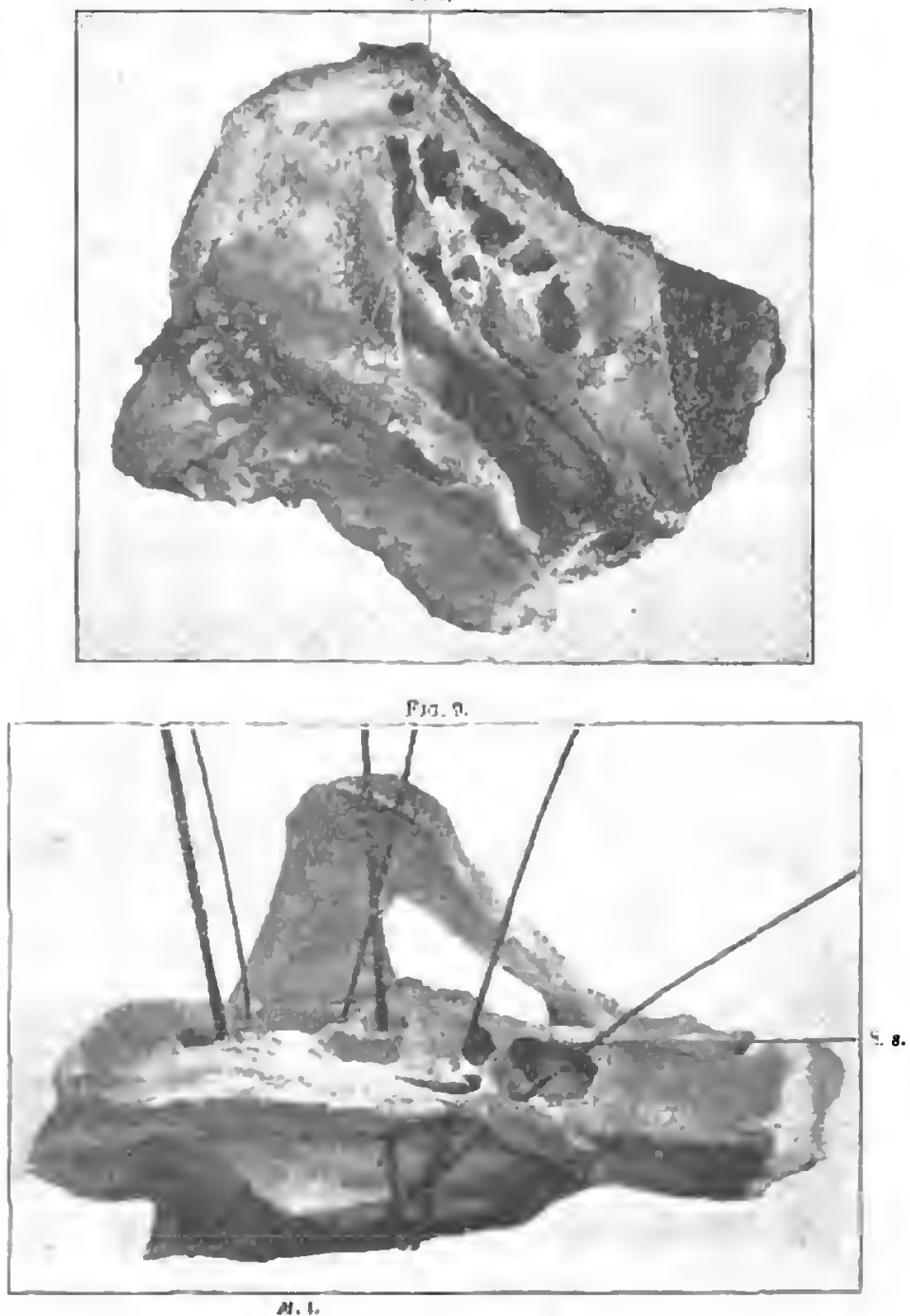

If. $t$., middie turbinated bone. S. 8., sphenoidal sinus.

A bristle is seen passing from the infundibulum out through a cavity in the cancellous tissue of the frontal bone.

Fig. 9 shows the external wall of the right nasal fossa of a child 
three years and eight months of age. Horizontal section has been made through the ethmoidal region so as to uncap these cells and

$$
\text { F. b. }
$$

FIn. 10.

A. c. $c$

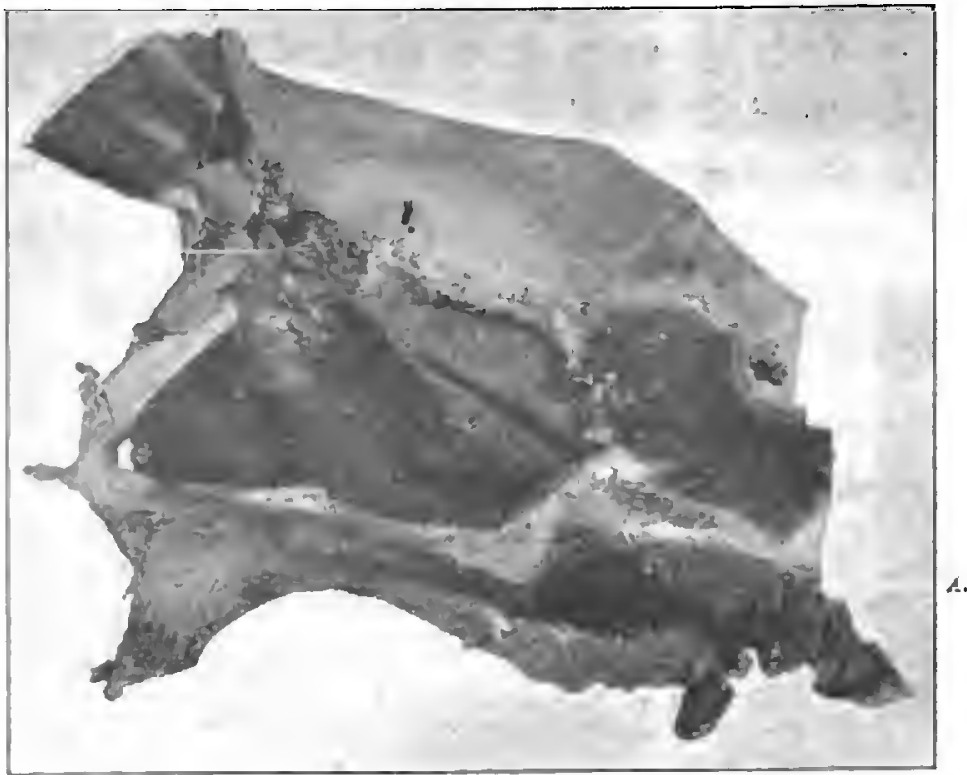

$F . b .$, fruatal bone. A. e. c., anterior ethrotdal cell, bong. wall removed. $A .$, alenold grow

A.e. c.

Fio. 11.

A. e. 6 .

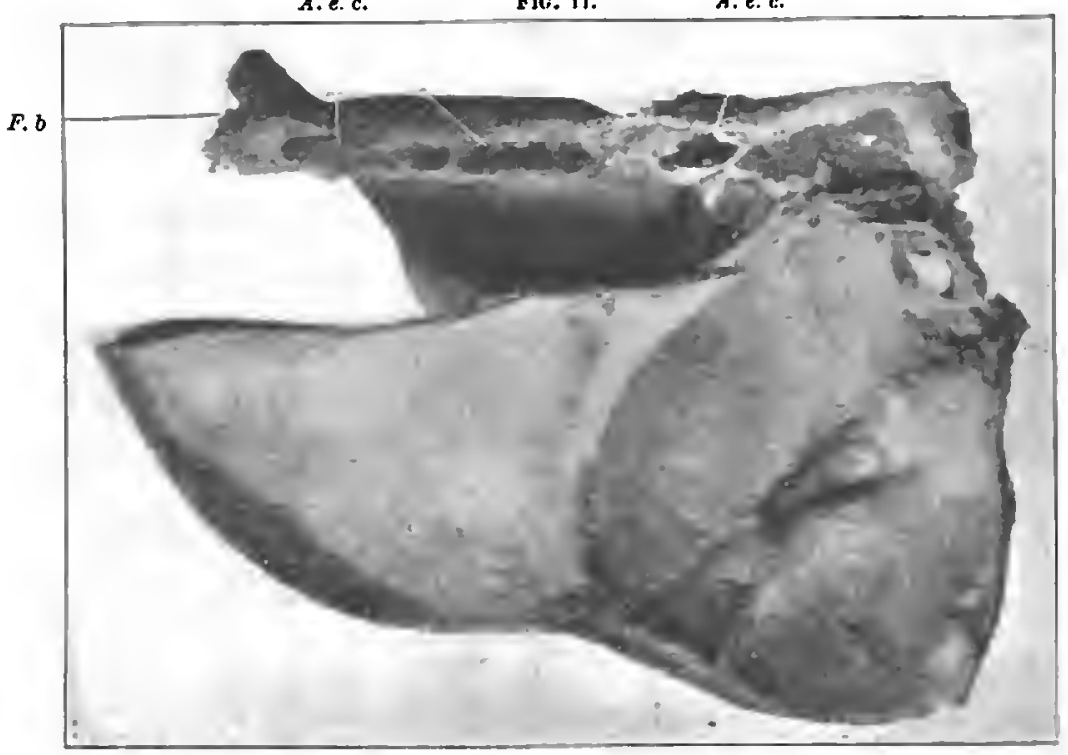


the sphenoidal sinus. The bone is tilted over so as to show the external wall of the nasal fossa and the ethmoidal cells and sphe-

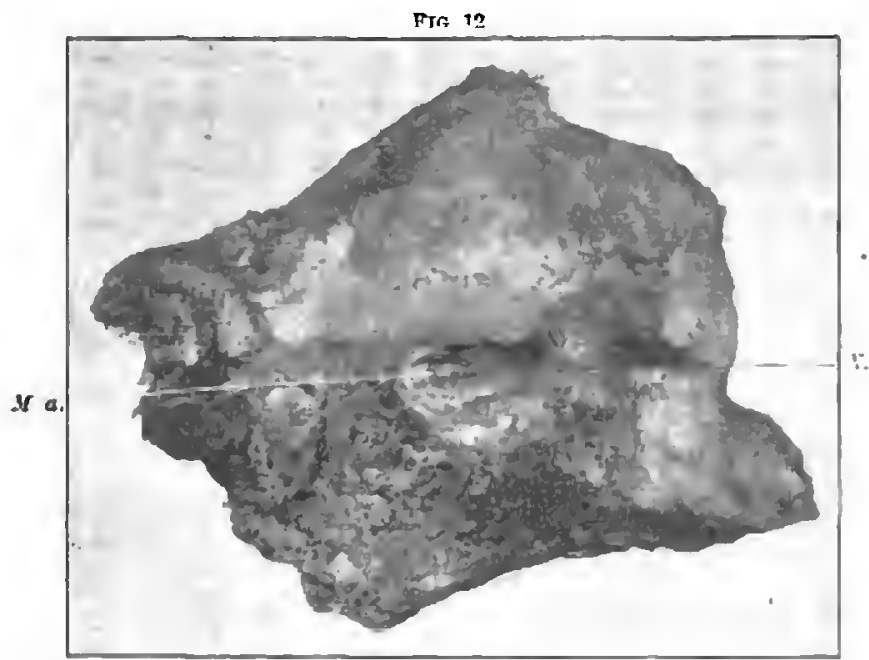

A. wop of twoth sucket. At. a., maxiliary atirum.

Fig. 13.

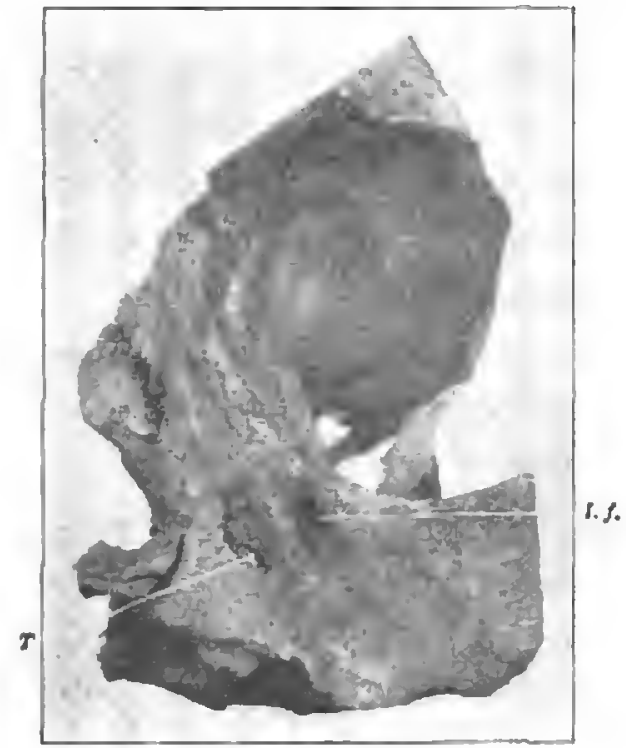

I. $f$., infraorbital foramen. $T$, top of tooth.

noidal sinus on the top. Bristles passing through the anterior ethmoidal cells are seen to emerge below the middle turbinated, 
while those through the posterior cells and the sphenoidal sinus emerge above the middle turbinated. Cells are well developed. This child had a perfectly free nasopharynx.

Fig. 10 shows the right nasal fossa through the fenestrated nasal septum, anterior half of middle turbinated having been removed to expose the hiatus semilunaris. Through this gutter the anterior ethmoidal cell has been packed with red worsted. A coronal section has been made through the vertical portion of the frontal bone and the anterior flap turned out to show zone of compact bone through centre of cancellous tissue. This may illustrate the formation of the bony septa so frequently found in the frontal sinus.

Fra. 14.

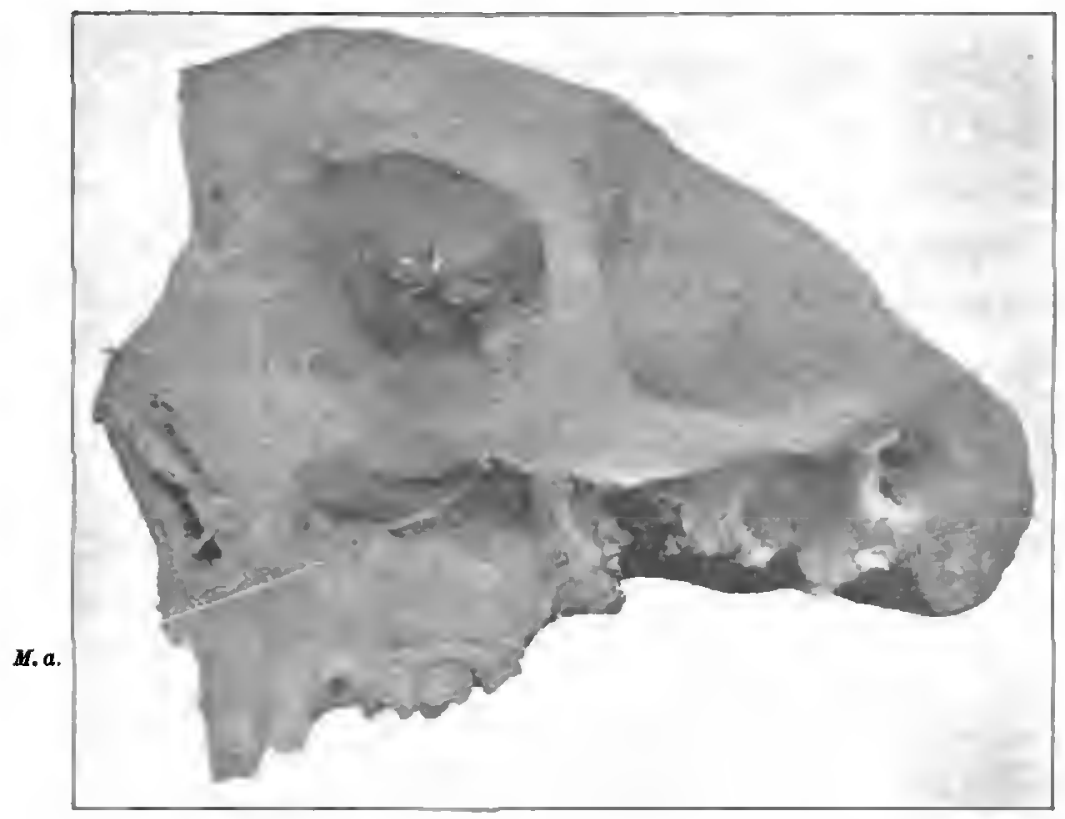

There is no frontal sinus in this case. The specinen is from a child seven years old, and the nasopharynx is to be seen much encroached upon by adenoid growths.

Fig. 11 shows horizontal section through the ethinoid region of the left side of the head and from the same child as Fig. 10. I wish especially to call your attention to the poor development of all the pneumatic cells in this specimen.

Fig. 12 shows the antrum in a child three years old opened through the external wall of the superior maxillary. The dark line drawn on the picture indicates the top of the tooth socket of the second or permanent tooth. 
Fig. 13 shows the anterior surface of the superior maxillary bone from a child seven years of age. Second teeth have not come down

FIG. 15.

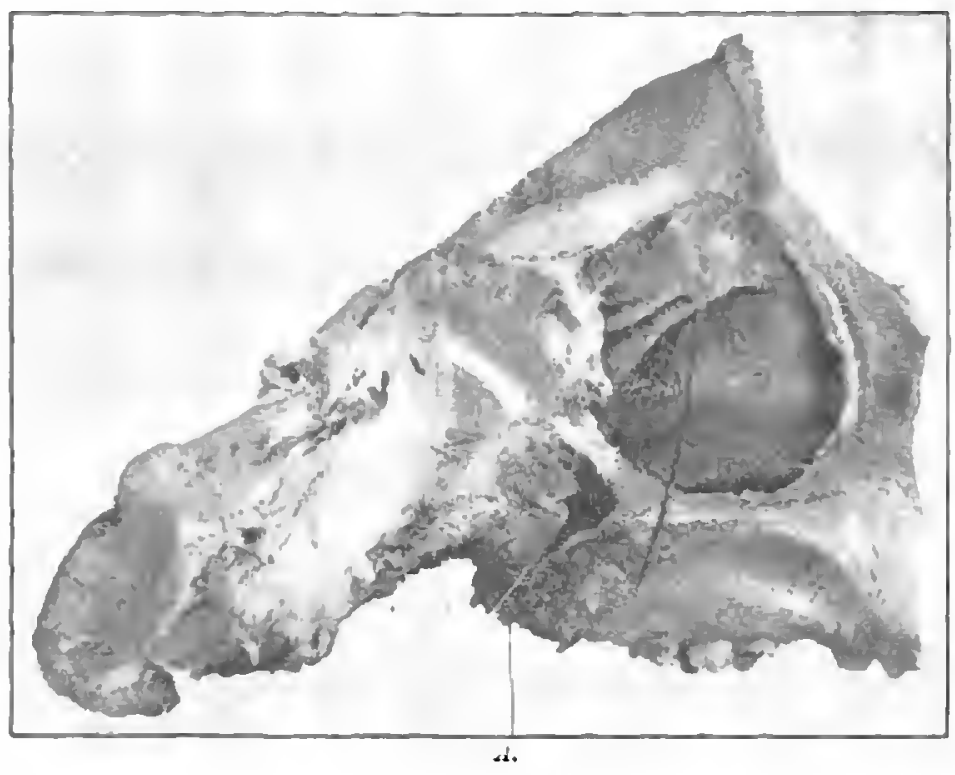

$A$, adenojỏ mass.

Fıg. 16.

I.

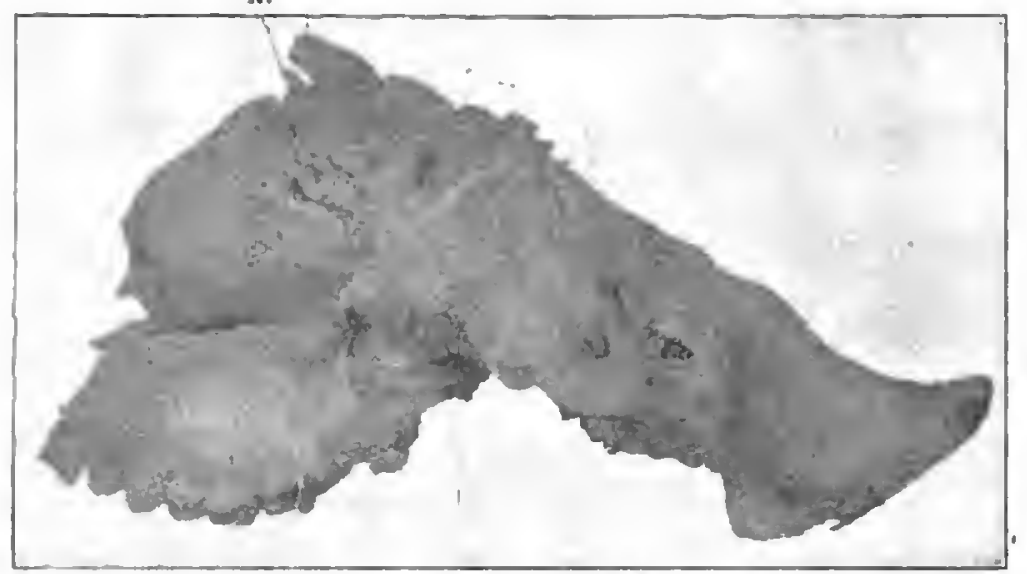

A., hining mowiorse of houkl swus.

and the top of canine tooth can be seen in the notch immediately below the infraorbital foramen. This picture is shown to illustrate 
how small a space we have for operating on the antrum even in a child seven years of age.

Fre. 17.

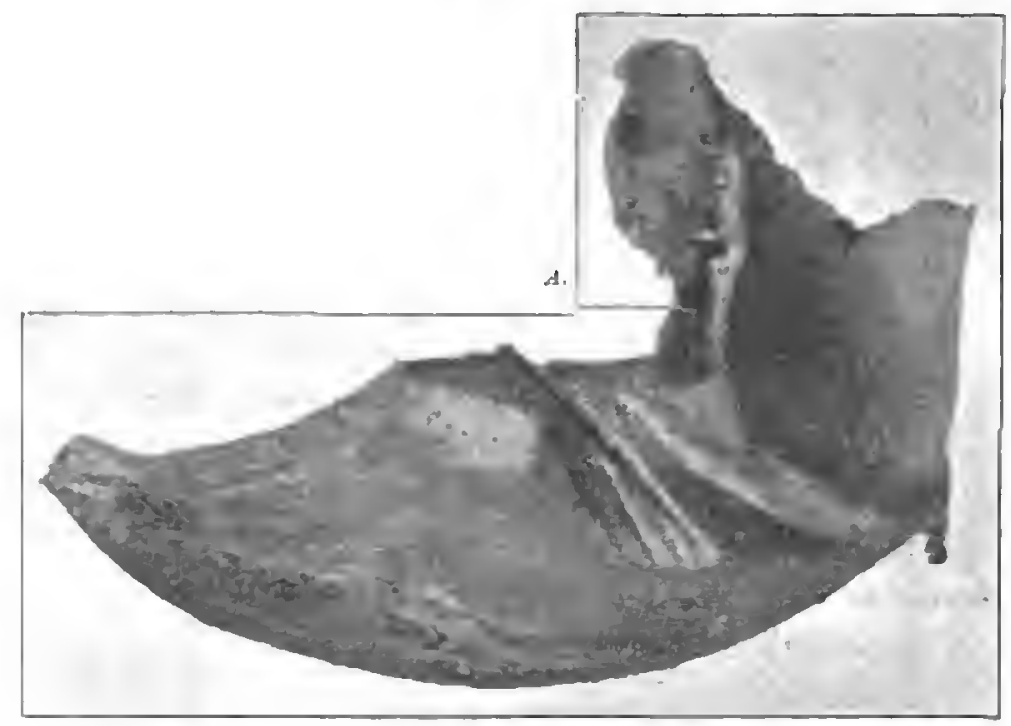

A., depression botween orbital plates.

Firs 18

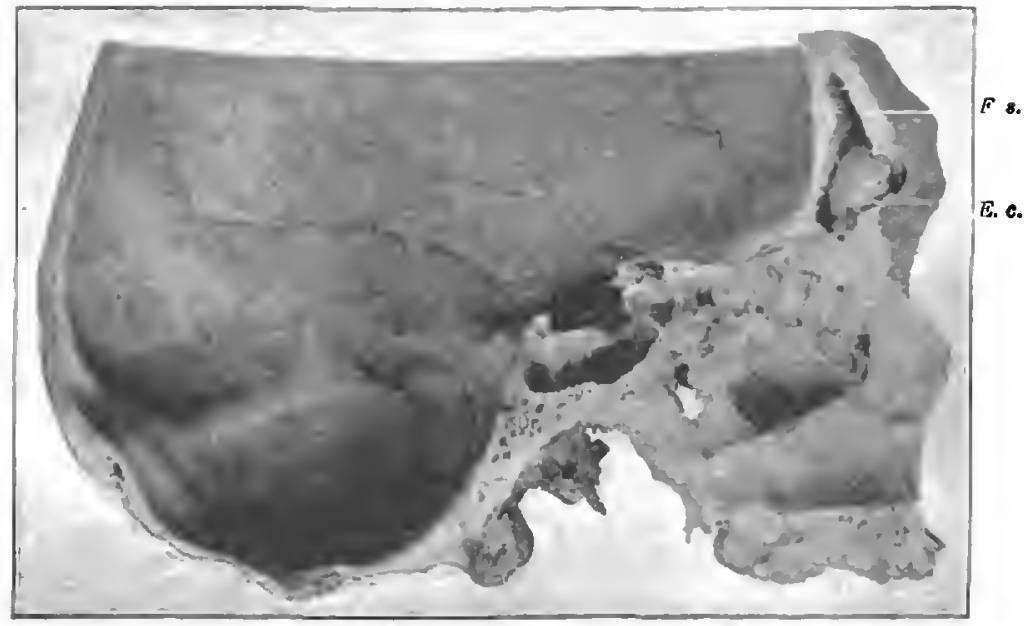

F. 8., trontal sinus. E. C., elbmolagl cell wilnin Irontai sinus.

Fig. 14 shows the external surface of the superior maxillary of a child nine years of age. The anterior wall of the antrum bas been removed, leaving the mucous lining in situ. This illustrates how 
much greater space is had for operating on the maxillary antrum after the descent of the second or permanent teeth.

Fig. 15 shows the external wall of the left nasal fossa through the fenestrated septum in a child nine years old, the middle turbinated and anterior half of the superior turbinated having been removed. The bristle seen passes through the infundibulum into the anterior ethmoidal cell. There is no frontal sinus. I wish to call attention to the enormous adenoid mass in the vault of the naso-pharynx. All the sinuses in this child were poorly developed.

Fig. 16 shows the external wall of the right nasal fossa of a child nine years old. The specimen has been so posed as to look distorted, but that is only for the purpose of showing the extent of the

Fı. 19.

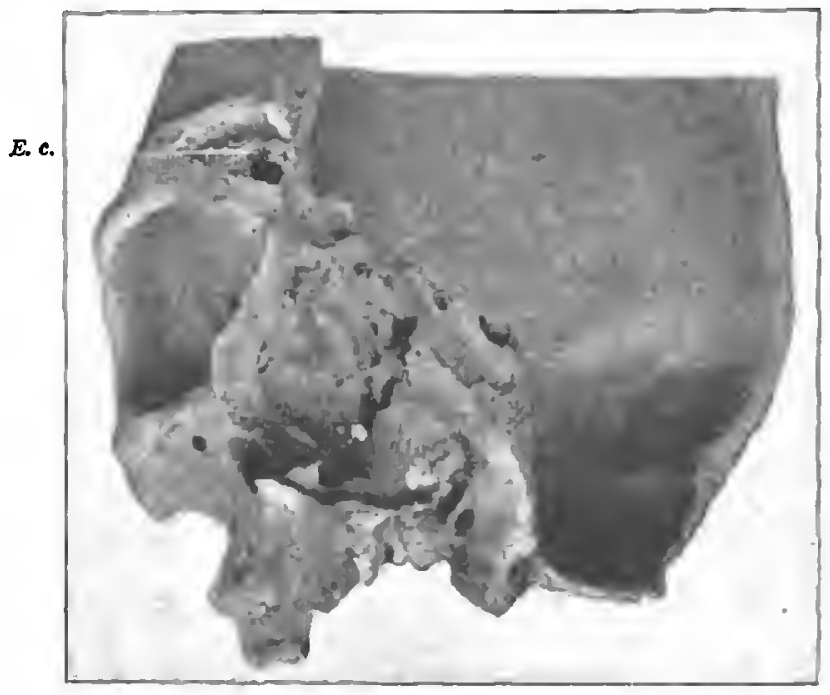

E. c., ethmotdal cell, Hlling troutal slnus.

frontal-sinus development. The lining membrane of the frontal sinus has been dissected away from the bone and may be seen in the upper left-hand corner of the figure.

Fig. 17 shows the frontal bone of an adult in which no frontal sinus could be found unless the depression seen between the two orbital plates of the frontal bone be so considered. It is very shallow and is merely the complement or the external wall of an anterior ethmoidal cell.

Fig. 18 is from a specimen kindly loaned me by Dr. H. M. Flower, of Toledo, Ohio. It shows an interesting condition in the frontal sinus. 'The frontal sinus is large and contains a very large ethmoidal cell. This figure illustrates how easily one might get into trouble even from an external operation for a frontal sinusitis. At the ordinary point of opening one would enter immediately this large 
ethmoidal cell and might easily satisfy himself that he had cleaned out the entire frontal sinus without even having entered it.

Fig. 19 is from the other half of the same head as Fig. 18. In this picture an ethmoidal cell is seen to fll completely the frontal sinus of this side.

\title{
A CASE OF PARINAUD'S CONJUNCTIVITIS. ${ }^{1}$
}

\author{
By William Campeell Posey, M.D., \\ OF PHILADELPHIA.
}

ON October 20, 1898, I was consulted by Dr. X., a surgeon of volunteers, who had just returned from Porto Rico. While there, in charge of one of the hospitals, he had contracted an inflammation of his right eye, which he thought was of a gonorrhoeal nature, as many cases of that disease were under his care when the eye became affected. When the eye was first inflamed, he said that the lids were swollen and were bathed in quite a copious mucopurulent secretion. The conjunctiva was also swollen and was studded with granules not unlike those of granular conjunctivitis. The inflammation of the eye, however, was not of the violent type which is usual in gonorrhœal ophthalmia, and did not interfere with his continuing his surgical duties. Washes of boric acid were employed, and the eye was cauterized upon several occasions with nitrate of silver. Notwithstanding this treatment, the inflammation of the eye persisted; the fellow-eye, however, remained unaffected. About three weeks after the appearance of the ocular inflammation a swelling was noticed in one of the small preauricular glands, and shortly after this the parotid gland itself of the same side was found to be affected. Signs of suppuration developing in the gland, an incision was made into it, and exit given to a small quantity of pus. Shortly after this, as the ocular inflammation persisted and his general condition was below par, he was sent home for further treatment.

When first seen by me, six weeks after the first appearance of the ocular symptoms, it was noted that both the upper and the lower lid of the right eye were much swollen, and that their edges were moistened by a slight mucopurulent discharge. Upon eversion of the lids the swelling was found to be occasioned by a marked thickening of the conjunctiva, especially in the folds occupying the fornix of both lids. From these folds were hanging a number of granulations which were much enlarged and were distinctly pedunculated, being at least an eighth of an inch long; between these were smaller granulations, which presented somewhat of a

1 Read before the Ophthalmological section of the College of Physicians of Phlladelphia, October 15, 1904. 